\title{
A cohort study examining emergency department visits and hospital admissions among people who use drugs in Ottawa, Canada
}

Claire E. Kendall ${ }^{1 *}$ (D), Lisa M. Boucher ${ }^{1}$, Amy E. Mark² $^{2}$ Alana Martin ${ }^{3}$, Zack Marshall ${ }^{4}$, Rob Boyd ${ }^{5}$, Pam Oickle ${ }^{6}$, Nicola Diliso ${ }^{7}$, Dave Pineau ${ }^{7}$, Brad Renaud ${ }^{7}$, Tiffany Rose ${ }^{7}$, Sean LeBlanc ${ }^{7,8}$, Mark Tyndall, ${ }^{9}$ Olivia M. Lee ${ }^{10}$ and Ahmed M. Bayoumi $2,11,12$

\begin{abstract}
Background: The health of people who use drugs (PWUD) is characterized by multimorbidity and chronicity of health conditions, necessitating an understanding of their health care utilization. The objective of this study was to evaluate emergency department (ED) visits and hospital admissions among a cohort of PWUD.

Methods: We used a retrospective observational design between 2012 and 2013. The population was a marginalized cohort of PWUD (the PROUD study) for whom survey data was linked $(n=663)$ to provincial health administrative data housed at the Institute for Clinical Evaluative Sciences. We constructed a 5:1 comparison group matched by age, sex, income quintile, and region. The main outcomes were defined as having two or more ED visits, or one or more hospital admissions, in the year prior to survey completion. We used multivariable logistic regression analyses to identify factors associated with these outcomes.

Results: Compared to the matched cohort, PWUD had higher rates of ED visits (rate ratio [RR] 7.0; 95\% confidence interval $[95 \% \mathrm{CI}] 6.5-7.6)$ and hospitalization (RR 7.7; 95\% Cl 5.9-10.0). After adjustment, factors predicting more ED visits were receiving disability (adjusted odds ratio [AOR] 3.0; 95\% Cl 1.7-5.5) or income assistance (AOR 2.7; 95\% Cl 1.5-5.0), injection drug use (AOR 2.1; 95\% Cl 1.3-3.4), incarceration within 12 months (AOR 1.6; 95\% Cl 1.1-2.4), mental health comorbidity (AOR $2.1 ; 95 \% \mathrm{Cl} 1.4-3.1$ ), and a suicide attempt within 12 months (AOR $2.1 ; 95 \% \mathrm{Cl} 1.1-3.4$ ). Receiving methadone (AOR $0.5 ; 95 \% \mathrm{Cl} 0.3-0.9$ ) and having a regular family physician (AOR $0.5 ; 95 \% \mathrm{Cl} 0.2-0.9$ ) were associated with lower odds of having more ED visits. Factors associated with more hospital admissions included Aboriginal identity (AOR 2.4; 95\% Cl 1.4-4.1), receiving disability (AOR 2.4; 95\% Cl 1.1-5.4), non-injection drug use (opioids and non-opioids) (AOR 2.2; 95\% Cl 1.1-4.4), comorbid HIV (AOR 2.4; 95\% Cl 1.2-5.6), mental health comorbidity (AOR 2.4; 95\% Cl 1.3-4.2), and unstable housing (AOR 1.9; 95\% Cl 1.0-3.4); there were no protective factors for hospitalization.
\end{abstract}

Conclusions: Improved post-incarceration support, housing services, and access to integrated primary care services including opioid replacement therapy may be effective interventions to decrease acute care use among PWUD, including targeted approaches for people receiving social assistance or with mental health concerns.

Keywords: People who use drugs, Emergency department visits, Hospital admissions, Health administrative data, Self-reported data, Matched control group, Prescription drug benefits, Multimorbidity, Primary care, Opioid replacement therapy

\footnotetext{
* Correspondence: ckendall@uottawa.ca

${ }^{1}$ Bruyère Research Institute, 43 Bruyère Street (Annex E), Ottawa, ON K1N

5C8, Canada

Full list of author information is available at the end of the article
} 


\section{Background}

People who use drugs habitually (PWUD) have multiple mental and physical health needs and a life expectancy 15 to 20 years shorter than that of the general population $[1,2]$. Many PWUD do not receive longitudinal care from a primary care physician who could support the management of their addiction and comorbid conditions [3-5]. Instead, care for PWUD is often addictionfocused and episodic, including visits to emergency departments [6-9]. In a 2001 Vancouver, British Columbia study, $74 \%$ of people who inject drugs visited an emergency room over 39 months, and $60 \%$ of these individuals had three or more visits [6]. These visits often resulted in hospital admission [6]. The design and delivery of the health system has a profound impact on these health inequities [10]. Following Rhode's concept of the "risk environment," in which the interaction of the physical, structural, and social spaces contributes to harm among people who use drugs [11], people who are already socially marginalized, such as those living in poverty and Indigenous peoples, may be at highest risk for receiving poor health care.

A small number of studies using survey data, health records data, or both have identified the following predictors of greater emergency department use or hospital admissions: injecting crystal methamphetamine or cocaine, greater frequency of injection drug use, HIVpositive status, unstable housing, greater use of primary care, having an overdose, experiencing an assault, recent incarceration, receiving methadone, mental health issues, female sex, reporting being unable to obtain needed health care services, and having private health insurance [6, 12-15]. However, the majority of studies to date have been limited in their focus on subpopulations of PWUD, such as those who inject drugs, are on opioid replacement therapy or in other treatment [1618], or are HIV positive [19-23], or on certain outcomes, such as infectious causes for acute care use [14, 24-26]. To the best of our knowledge, no studies have compared emergency department visits or hospital admissions among PWUD to those in the general community, nor made use of population-level administrative datasets to evaluate care for this population. An improved understanding of the rates of acute care use is critical for centres to anticipate care needs arising for PWUD, and given a large proportion of these visits may be preventable, an improved understanding of the determinants of these visits can identify potential areas for intervention [27]. In addition, given that drug use is an epidemic in evolution, in place, and in time, a contextual understanding of the characteristics of PWUD, and their implications for health services use is required to respond and adapt to drug policy environments.
The objectives of our study were to describe the rates of emergency department visits and hospital admissions by PWUD, compared to a matched population-based cohort and to determine the correlates of these encounters for this population. We used data from the Participatory Research in Ottawa: Understanding Drugs (PROUD) study [28], a communitybased cohort study of PWUD in Ottawa, Canada, where rates of hepatitis $\mathrm{C}$ and HIV are among the highest of any major Canadian city [3]. We linked PROUD data to administrative databases, yielding a dataset with rich information about individual characteristics and health services use.

\section{Methods}

\section{Setting and context}

Among Ottawa's the 3500 to 6000 people who use drugs in Ottawa, rates of Hepatitis C and HIV are among the highest of any major Canadian city [3, 29]. An estimated 2263 area residents take opioid agonist therapy [30], and among those on opioid agonist treatment in the province of Ontario in 2014/15, about 80\% took methadone [31]. Wait times for substance use treatment services is variable, with an average wait time from assessment to starting treatment of 29 days (source Ottawa Addictions Assessment and Referral Service, unpublished). Our region does not currently have supervised injection services.

\section{Participants}

The PROUD study has been described previously [28]. Briefly, we used peer-guided street-based recruitment using snowball sampling to enrol participants in a crosssectional survey study, focusing on socially and economically marginalized PWUD. Eligibility criteria included an age of at least 16 years and self-reported use of an illicit drug use other than marijuana by any route in the 12 months prior to the enrolment (March to December 2013). The survey was interviewer-administered and included questions about socio-demographic information, drug use, interpersonal variables (e.g., sexual history, community integration), environmental-structural variables (e.g., harm reduction, housing, legal matters), and health and health services use. Participants received a cash honoraria of \$20 Canadian for participation in the study. All PROUD activities were governed by a Community Advisory Committee of PWUD and allies.

Participants were also asked to consent to link their survey data to the administrative databases held at the Institute for Clinical Evaluative Sciences (ICES). ICES databases are made available to accredited researchers through a data sharing agreement with the Ontario Ministry of Health and Long-Term Care. The PROUD and 
ICES datasets were linked either deterministically, using unique, encoded identifiers derived from participants' reported Ontario Health Insurance Plan numbers, or probabilistically (when insurance numbers were unavailable) based on participants' names, dates of birth, and postal codes. Participants with duplicate enrolment were identified following linkage; the record with the most complete data was retained.

We used the following ICES databases: Registered Persons Database (demographic and mortality data for all residents eligible for provincial health care), Ontario Health Insurance Program (OHIP) billing claims system (about 95\% of physician services in Ontario), Community Health Centre database (encounter information for visits to Community Health Centres), Discharge Abstract Database (all hospital admission and discharge data), National Ambulatory Care Reporting System (emergency department visits), Client Agency Program Enrolment Registry (patient enrolment with individual primary care physicians), ICES Physician Database (physician demographic information, training, and practice setting), Corporate Provider Database (physician and group level data), Ontario Mental Health Reporting System (all admissions to designated mental health beds), Same Day Surgery database (all same day surgeries), CONTACT (eligibility summaries and yearly health services contact), Ontario Drug Benefits (prescription claims for individuals covered by the public system including those aged 65 and older and those receiving support from the Ontario Disability Support Program, Ontario Works (income assistance) and Trillium (a provincial catastrophic drug insurance program), Drug Identification Number database (drug list from Ontario Drug Benefits formularies, including generic names, trade names, and strengths), and Ontario HIV database (an ICES-derived cohort). We also used 2006 Statistics Canada Census data to infer income quintile by linking postal code of residence to the mean household income by dissemination area, which represents a standard geographic area typically consisting of 400 to 700 individuals.

To compare PROUD participants to the general population, we randomly selected control individuals, matched on age, sex, public health unit, and income quintile (using postal code) in a 5:1 ratio [32].

\section{Variable definitions}

We categorized gender using self-reported data in the PROUD survey except when gender was missing or when participants reported gender as "two-spirited" or "other", in which case we used ICES data (sex at birth). We excluded transgender individuals $(<6)$. We used postal code to assign neighborhood income into quintiles. We classified comorbidity using the Johns Hopkins Adjusted Clinical Groups Case-Mix Assignment software
(Sun Microsystems Inc., Santa Clara, CA) by assigning up to 32 distinct Aggregated Diagnosis Groups (ADGs) [33]. We categorized comorbidity as low ( $\leq 5 \mathrm{ADGs}$ ), medium (6-9 ADGs), or high ( $\geq 10$ ADGs), and we used validated ICES algorithms to classify the presence of mental health diagnoses and HIV [34, 35].

Ontario has several mechanisms of prescription drug benefits (Ontario Drug Benefits), including coverage for those aged 65 and older and those receiving support from the Ontario Disability Support Program, Ontario Works (income assistance), and Trillium (a provincial catastrophic drug insurance program). Ontario has distinct models of primary care with different reimbursement mechanisms, such as capitation with rostering of patients to physicians and organizational structures, such as the presence of interprofessional teams. We categorized primary care models according to whether they were community health centres or conventional practices, team-based or not, and whether reimbursement was based on capitation, fee for service payments, or enhanced fee for service [36]. Rostered participants were assigned to their primary care physician; non-rostered participants were assigned to the family physician who provided the majority of the costs of their primary care in the year prior to enrolment. We counted the number of primary care visits excluding visits that were exclusively for methadone therapy.

The majority of variables arising from PROUD survey data were dichotomized to yes versus no, with the no category including any non-yes response (including don't know/unsure, no answer, and missing responses, with up to 25 participants providing don't know/unsure responses, and up to 30 participants providing no answer responses). Missing responses usually occurred on subquestions due to skip patterns dictated by the responses to parent questions (and when the missing responses were not due to skipped sub-questions, they occurred for up to 20 participants across questions).

\section{Outcomes}

Our co-primary outcome measures were emergency department visits and hospital admissions in the year prior to enrolment after excluding maternity-related admissions and same-day surgeries. We categorized emergency department visits by acuity level using the Canadian Triage and Acuity Score (CTAS) from 1 (highest) to 5 (lowest). We ascertained diagnoses using the most responsible diagnosis for emergency department visits, and any diagnosis for hospital admission diagnoses.

\section{Analyses}

Comparative rates of emergency department visits and hospital admissions (number of events per year) between the PROUD participants and the matched cohort were 
stratified by gender and analyzed using chi-squared or Fisher's exact test for categorical variables and Wilcoxon rank sum tests for continuous variables. We used logistic regression to analyze variables associated with having two or more emergency department visits and to analyze variables associated with one or more hospital admission; we conducted these analyses both comparing PROUD participants to the matched cohort and within the PROUD cohort alone. We used a non-parsimonious approach to selecting covariates but excluded those that we judged likely to be collinear. Cell sizes of 6 or less are reported in aggregate only to preserve privacy. All statistical analyses were conducted using SAS statistical software, version 9.3 (SAS Institute Inc., Cary, NC). This study was approved by the institutional review board at Sunnybrook Health Sciences Centre, Toronto, Canada, and the Ottawa Health Sciences Network Research Ethics Board (OHSN-REB \#20120566-01H).

\section{Results}

Of 858 PROUD participants, 798 agreed to data linkage. We excluded participants without Ontario health insurance and those who were likely duplicate enrolments. Of the remaining 782 participants, 663 (85\%) were successfully linked. Among the analysis cohort, the median age was 41.4 years, $75.6 \%$ were male, $66.7 \%$ were in the lowest two income quintiles, and $78.3 \%$ received disability payments or income assistance (Table 1). Over half of PROUD participants had a mental health-related diagnosis other than substance use-related care. About equal proportions of PROUD participants and matched cohort individuals had a primary care physician but PROUD participants were more likely to receive care in a community health centre and had about three times as many primary care visits.

Compared to the matched cohort, PROUD participants had a significantly higher rate of emergency department visits ( 2.1 vs. 0.3 visits per year; rate ratio [RR] 7.0; 95\% confidence interval [95\% CI] 6.5 to 7.6) (Table 2). The rate ratio was similar among PROUD participants when we restricted analyses to men, women, and people with higher acuity visits (CTAS 1, 2 , or 3). PROUD participants were much more likely than controls to visit an emergency room for a mental health-related diagnosis, including both substance use-related visits (RR 150.0; 95\% CI 86.3 to 260.7) and other mental health visits (RR 16.0; 95\% CI 10.3 to 24.8). Rates among PROUD participants were also significantly higher than controls for infectious diseases (RR 12.0; 95\% CI 8.1 to 17.8), including soft tissue infection and pneumonia. In contrast to the matched cohort (from whom the number of visits were too few to report), PROUD participants also had measurable rates of cocaine-related visits (9.2 visits per 100 person-years), visits for overdose (4.7 visits per 100 person-years), self-harm (4.5 visits per 100 person-years), and opioid use (2.4 visits per 100 person-years).

Compared to the matched cohort, PROUD participants had a significantly higher rate of hospital admissions (RR 7.7; 95\% CI 5.9 to 10.0) (Table 3). Rates were higher for women than for men (30.9 visits per 100 person-years vs. 18.2, respectively). However, the rate ratios comparing PROUD participants to individuals in the matched cohort were similar for men (7.2) and women (8.6). Among PROUD participants, the most common reasons for hospital admission were substance use (7.7 admissions per 100 person-years), mental health excluding substance use (4.4 admissions per 100 person-years), and infectious causes (4.4 admissions per 100 personyears); pneumonia and soft tissue infections accounted for most of the infection-related admissions.

After adjusting for HIV status, mental health diagnosis, receipt of disability or income assistance, and linkage with primary care, PROUD participants were still much more likely than individuals from the matched cohort to have two or more emergency department visits (adjusted odds ratio [AOR] 3.3; 95\% CI 2.4 to 4.7), or to have one or more hospital admissions (AOR 2.2; 95\% CI 1.4 to 3.6) (Table 4).

When we analyzed only PROUD participants, after adjustment, the strongest independent associations with emergency department use, classified as two or more visits, were receiving disability payments (AOR 3.0; $95 \%$ CI 1.7 to 5.5 ) or income assistance (AOR 2.7; $95 \%$ CI 1.5 to 5.0 ), any injection drug use in the previous 12 months (AOR 2.1; 95\% CI 1.3 to 3.4), incarceration in the previous 12 months (AOR 1.6; 95\% CI 1.1 to 2.4), mental health comorbidity (AOR 2.1; $95 \%$ CI 1.4 to 3.1), and having a suicide attempt in the previous 12 months (AOR 2.1; 95\% CI 1.1 to 3.4) (Table 5). Receiving methadone (AOR 0.5; 95\% CI 0.3 to 0.9 ) and having a regular family physician (AOR $0.5 ; 95 \%$ CI 0.2 to 0.9 ) were associated with lower odds of having two or more emergency department visits. In a similar adjusted analysis of one or more hospital admissions, the strongest associations were with self-identified Aboriginal identity (AOR 2.4; 95\% CI 1.4 to 4.1), receiving disability payments (AOR 2.4; 95\% CI 1.1 to 5.4), noninjection drug use (both opioids and non-opioids) (AOR 2.2; 95\% CI 1.1 to 4.4), comorbid HIV (AOR 2.4; $95 \%$ CI 1.2 to 5.6), mental health comorbidity (AOR 2.4; 95\% CI 1.3 to 4.2 ), and unstable housing (AOR 1.9; 95\% CI 1.0 to 3.4). No factors were associated with lower odds of having one or more hospital admissions. 
Table 1 Characteristics of PROUD participants $(n=663)$, and an Ontario population $(n=3,315)$ matched by age, sex, public health unit, and neighborhood income quintile

\begin{tabular}{|c|c|c|c|}
\hline Characteristic & & $\begin{array}{l}\text { PROUD } \\
(N=663) \\
(n / N,(\%)) \\
\end{array}$ & $\begin{array}{l}\text { Matched cohort } \\
(N=3315) \\
(n / N,(\%))\end{array}$ \\
\hline Age & & $41.4(10.8)$ & $41.0(10.8)$ \\
\hline \multirow[t]{5}{*}{ Age category } & $<=24$ & $54(8.1)$ & $291(8.8)$ \\
\hline & 25 to 34 & $134(20.2)$ & $676(20.4)$ \\
\hline & 35 to 44 & $182(27.5)$ & $937(28.3)$ \\
\hline & 45 to 54 & $229(34.5)$ & $1126(34)$ \\
\hline & $>=55$ & $64(9.7)$ & $285(8.6)$ \\
\hline \multirow[t]{2}{*}{$\operatorname{Sex}^{\mathrm{a}}$} & Male & $501(75.6)$ & $2505(75.6)$ \\
\hline & Female & $162(24.4)$ & $810(24.4)$ \\
\hline \multirow[t]{3}{*}{ Local Health Integration Network } & Champlain & $610(92)$ & $3315(100)$ \\
\hline & Other & $35(5.3)$ & \\
\hline & Out of province/missing & $18(2.7)$ & \\
\hline \multirow[t]{6}{*}{ Income quintile } & 1 (lowest) & $246(37.1)$ & $1230(37.1)$ \\
\hline & 2 & $196(29.6)$ & $980(29.6)$ \\
\hline & 3 & $144(21.7)$ & $720(21.7)$ \\
\hline & 4 & $36(5.4)$ & $180(5.4)$ \\
\hline & 5 (highest) & $28(4.2)$ & $169(5.1)$ \\
\hline & Missing & $13(2)$ & $36(1.1)$ \\
\hline \multirow[t]{3}{*}{ Prescription drug benefits } & Ontario Works & $164(24.7)$ & $111(3.4)$ \\
\hline & Ontario Disability Support Program & $342(51.6)$ & $213(6.4)$ \\
\hline & Other, including no coverage & $157(23.7)$ & $2991(90.2)$ \\
\hline \multirow{3}{*}{$\begin{array}{l}\text { Comorbidity (\# of aggregated diagnosis } \\
\text { groups (ADGs) in } 2 \text { year prior to cohort } \\
\text { entry) }\end{array}$} & Low comorbidity (0-5 ADGs) & $273(41.2)$ & $2048(61.8)$ \\
\hline & Medium comorbidity (6-9 ADGs) & $220(33.2)$ & $1072(32.3)$ \\
\hline & High comorbidity (> = 10 ADGs) & $170(25.6)$ & $195(5.9)$ \\
\hline $\begin{array}{l}\text { Comorbid mental health conditions } \\
\text { (excluding substance use diagnoses) }\end{array}$ & & $362(54.6)$ & $595(18)$ \\
\hline Comorbid HIV & & $50(7.5)$ & $16(0.5)$ \\
\hline Has a regular family physician & & $542(81.8)$ & $2915(87.9)$ \\
\hline \multirow[t]{6}{*}{ Primary care model } & Team-based capitation & $103(15.5)$ & $522(15.8)$ \\
\hline & Non-team-based capitation & $61(9.2)$ & $894(27)$ \\
\hline & Enhanced fee for service & $223(33.6)$ & $1177(35.5)$ \\
\hline & Traditional fee for service & $68(10.3)$ & $260(7.8)$ \\
\hline & Community health centre & $87(13.1)$ & $62(1.9)$ \\
\hline & Orphan patients (unrostered) & $121(18.3)$ & $400(12.1)$ \\
\hline $\begin{array}{l}\text { \# of outpatient primary care visits } \\
\text { in } 1 \text { year prior to survey completion } \\
\text { (non-methadone) }\end{array}$ & & $10.2(16.9)$ & $3.2(5.1)$ \\
\hline
\end{tabular}

\footnotetext{
"We categorized gender using self-reported data in the PROUD survey except when gender was missing or when participants reported gender as "two-spirited" or
} "other", in which case we used ICES data (sex at birth). We excluded transgender individuals $(<6)$

\section{Discussion}

We used a combination of rich self-reported data and robust health administrative data to assess the use of acute care services among PWUD. Our main finding is that PWUD continue to use emergency and hospital services at disproportionately high rates compared to the general population (approximately seven to eight times more frequently) and that most of this use is related to drug use and other mental health-related problems. Our results underscore the significant burden of mental health illness experienced by PWUD, and the ongoing need for comprehensive 
Table 2 Rates of emergency department visits among PROUD participants ( $n=663)$ compared to an Ontario population $(n=3315)$ matched by age, sex, public health unit, and neighborhood income quintile

\begin{tabular}{|c|c|c|c|c|c|}
\hline \multirow{2}{*}{$\begin{array}{l}\text { Emergency visit } \\
\text { characteristic }\end{array}$} & \multicolumn{2}{|c|}{ PROUD } & \multicolumn{2}{|c|}{ Control } & \multirow{2}{*}{$\begin{array}{l}\text { Rate Ratio } \\
\text { PROUD/Control }(95 \% \\
\text { CI)* }\end{array}$} \\
\hline & $\mathbf{N}$ & $\begin{array}{l}\text { Mean (SD) } \\
\text { visits/year }\end{array}$ & $\mathbf{N}$ & $\begin{array}{l}\text { Mean (SD) } \\
\text { visits/year }\end{array}$ & \\
\hline All & 1404 & $2.118(5.789)$ & 997 & $0.301(1.279)$ & 7.04 (6.49 to 7.64$)$ \\
\hline Men & 976 & $1.948(5.842)$ & 721 & $0.288(1.372)$ & $6.77(6.15$ to 7.45$)$ \\
\hline Women & 428 & $2.642(5.605)$ & 276 & $0.341(0.933)$ & 7.75 (6.66 to 9.02$)$ \\
\hline $\begin{array}{l}\text { Canadian Triage and Acuity } \\
\text { Score } 1 / 2 / 3 \text { (higher acuity) }\end{array}$ & 1130 & $1.704(5.045)$ & 664 & $0.2(0.877)$ & $8.51(7.73$ to 9.36$)$ \\
\hline \multicolumn{6}{|l|}{$\begin{array}{l}\text { Diagnoses (most responsible } \\
\text { diagnosis per encounter): }\end{array}$} \\
\hline $\begin{array}{l}\text { Substance use (including } \\
\text { alcohol and cannabis) }\end{array}$ & 390 & $0.588(3.885)$ & 13 & $0.004(0.116)$ & 150.00 (86.32 to 260.66$)$ \\
\hline $\begin{array}{l}\text { Mental health (excluding } \\
\text { substance use) }\end{array}$ & 83 & $0.125(0.577)$ & 26 & $0.008(0.095)$ & $15.96(10.27$ to 24.8$)$ \\
\hline $\begin{array}{l}\text { Infectious causes (including } \\
\text { endocarditis, pneumonia, } \\
\text { soft tissue, tuberculosis) }\end{array}$ & 84 & $0.127(0.469)$ & 35 & $0.011(0.126)$ & $12.00(8.09$ to 17.8$)$ \\
\hline Soft tissue & 68 & $0.103(0.417)$ & 24 & $0.007(0.104)$ & $14.17(8.9$ to 22.56$)$ \\
\hline Pneumonia & 14 & $0.021(0.181)$ & 11 & $0.003(0.067)$ & $6.36(2.89$ to 14.02$)$ \\
\hline \multicolumn{6}{|l|}{ Any diagnosis: } \\
\hline Cocaine related & 61 & $0.092(0.904)$ & & & \\
\hline Overdose related & 31 & $0.047(0.262)$ & & & \\
\hline Self-harm related & 30 & $0.045(0.277)$ & & & \\
\hline Opioid related & 16 & $0.024(0.163)$ & & & \\
\hline
\end{tabular}

*Shaded cells reflect cases $<=6$ participants

and continuing mental health care. Whether such supports can avert use of acute care services is a topic for future research.

We found that receiving disability or income assistance were associated with increased use of emergency departments or hospital admissions. Participants who were HIVpositive were more likely to be hospitalized. Aboriginal ethnicity was also associated with increased hospitalization. These findings likely relate to the significant and synergistic effects of poverty, structural racism, and comorbidities on individuals' health and the incomplete amelioration of these effects by current public assistance programs [37, 38].

We identified two factors that may be important in averting use of acute care services. Receipt of methadone was associated with an approximately 50\% lowered risk of visiting an emergency department at least twice in a year. Having a regular family physician was associated with a similar reduction in emergency department visits. In contrast to some findings [12, 39], our study supports linkage to a regular source of primary care to optimize the health of PWUD [40]. We found that having unstable housing was associated with an almost twofold increased risk of hospitalization; programs that target people who are homeless have been shown to reduce the number of hospitalizations, the length of hospital stays, and the number of emergency department visits [41].

Being detained in jail overnight or longer in the last 12 months was associated with higher odds of having 
Table 3 Rates of hospital admissions among PROUD participants $(n=663)$ compared to an Ontario population $(n=3315)$ matched by age, sex, public health unit, and neighborhood income quintile

\begin{tabular}{|c|c|c|c|c|c|}
\hline \multirow[t]{2}{*}{ Hospital admission characteristic } & \multicolumn{2}{|c|}{ PROUD } & \multicolumn{2}{|c|}{ Control } & \multirow{2}{*}{$\begin{array}{l}\text { Rate ratio PROUD/ } \\
\text { control }(95 \% \mathrm{Cl})\end{array}$} \\
\hline & $N$ & Mean (SD) visits/year & $\bar{N}$ & Mean (SD) visits/year & \\
\hline All & 141 & $0.213(0.608)$ & 92 & $0.028(0.249)$ & 7.66 (5.89 to 9.97) \\
\hline Males & 91 & $0.182(0.549)$ & 63 & $0.025(0.187)$ & $7.22(5.24$ to 9.96$)$ \\
\hline Females & 50 & $0.309(0.758)$ & 29 & $0.036(0.382)$ & $8.62(5.46$ to 13.62$)$ \\
\hline \multicolumn{6}{|l|}{ Diagnoses (any diagnosis per encounter) } \\
\hline Substance use (including alcohol and cannabis) & 51 & $0.077(0.304)$ & 9 & $0.003(0.052)$ & 28.33 (13.95 to 57.55 \\
\hline Mental health (excluding substance use) & 29 & $0.044(0.274)$ & 7 & $0.002(0.052)$ & 20.71 (9.07 to 47.29$)$ \\
\hline
\end{tabular}

two or more emergency department visits. To date, Ottawa has had a prohibitionist drug policy environment: people in our cohort have experienced negative interactions with police arising from their drug use that has led to frequent incarcerations, with $77 \%$ of our cohort having had spent one or more nights in jail in the year prior to survey completion and 30\% experiencing "red zoning", the geographic restriction of access to certain areas of the city by police. Transitioning from incarceration is a highly destabilized period, contributing to greater emergency department use and poor linkages to primary care despite a high prevalence of chronic disease in this population [42, 43]. Furthermore, this association also speaks to the contribution of the criminal justice system in perpetuating harms among people who use drugs [11].

A strength of our study is the use of community-based participatory research methods to obtain survey data on a highly disadvantaged population, and the use of population-level data to characterize health care use in a setting with universal health insurance. However, our study has limitations. The PROUD survey relied on self-reported data which may be prone to social desirability or other reporting biases. Participants were asked about practices that are highly stigmatized or illegal, which may contribute to underreporting of high-risk practices. We used a streetbased peer recruitment approach to reach "hidden populations" in order to improve representativeness over standard recruitment methods [28, 44], however, it is possible that our findings are not widely generalizable. PROUD was a cross-sectional study so we are unable to look at trends over time, including changes in drug use. Finally, ICES data are collected for administrative rather than research purposes. Social variables such as income are ascertained using neighborhood-level metrics (postal codes). However, linkage to PROUD survey data improved the detail of social level variables available for our population.

\section{Conclusions}

In conclusion, our study quantified the substantial use of acute care services among PWUD, in particular for mental health and addiction-related issues. Our findings underscore the intersection of multi-level, socialstructural factors [45] that influence health care use among PWUD, such as mental health and physical health comorbidity, poverty, social instability, structural racism, and the persistent criminalisation of drug use. Future research should highlight the potential role for integrated primary care and housing services and

Table 4 Multivariable logistic regression of PROUD participation on 2+ emergency department visits and 1+ hospital admission, adjusted for listed covariates

\begin{tabular}{|c|c|c|c|c|c|}
\hline Covariate & & $\begin{array}{l}2+\text { ED visits } \\
\operatorname{AOR}(95 \% \mathrm{Cl})\end{array}$ & $\begin{array}{l}2+\text { low acuity ED visits } \\
\text { AOR }(95 \% \text { Cl) }\end{array}$ & $\begin{array}{l}2+\text { high acuity ED visits } \\
\text { AOR }(95 \% \mathrm{Cl})\end{array}$ & $\begin{array}{l}\text { 1+ hospital admission } \\
\text { AOR }(95 \% \mathrm{Cl})\end{array}$ \\
\hline \multirow[t]{2}{*}{ PROUD participant } & Yes & $3.33(2.38$ to 4.66$)$ & $1.42(0.79$ to 2.57$)$ & 4.53 (3.04 to 6.76) & $2.24(1.41$ to 3.55$)$ \\
\hline & No & Ref & Ref & Ref & Ref \\
\hline \multirow[t]{2}{*}{ Comorbid HIV } & Yes & 2.67 (1.06 to 6.76$)$ & 0.40 (0.07 to 2.14) & $5.44(1.52$ to 19.49$)$ & 2.58 (0.82 to 8.09$)$ \\
\hline & No & Ref & Ref & Ref & Ref \\
\hline \multirow{2}{*}{$\begin{array}{l}\text { Comorbid mental health diagnosis (excluding } \\
\text { substance use-related diagnoses) }\end{array}$} & Yes & 2.67 (1.96 to 3.64$)$ & 2.77 (1.55 to 4.96$)$ & $3.56(2.4$ to 5.26$)$ & 2.37 (1.46 to 3.86$)$ \\
\hline & No & Ref & Ref & Ref & Ref \\
\hline \multirow[t]{2}{*}{ Prescription drug benefits (any) } & Yes & 2.75 (1.90 to 3.98$)$ & $7.34(3.51$ to 15.31$)$ & 2.56 (1.61 to 4.07$)$ & $4.72(2.70$ to 8.23$)$ \\
\hline & No & Ref & Ref & Ref & Ref \\
\hline \multirow[t]{2}{*}{ Has a regular family physician } & Yes & 0.26 (0.15 to 0.47$)$ & 0.66 (0.24 to 1.84$)$ & 0.22 (0.11 to 0.44$)$ & $0.64(0.32$ to 1.3$)$ \\
\hline & No & Ref & Ref & Ref & Ref \\
\hline
\end{tabular}


Table 5 Multivariable logistic regression of PROUD participant characteristics associated with 2+ emergency department visits or 1+ hospital admission, adjusted for listed covariates

\begin{tabular}{|c|c|c|c|}
\hline Variable & & $\begin{array}{l}\text { 2+ ED visits } \\
\text { AOR }(95 \% \mathrm{Cl})\end{array}$ & $\begin{array}{l}\text { 1+ hospital admission } \\
\text { AOR }(95 \% \mathrm{Cl})\end{array}$ \\
\hline Age (per year) & & 0.98 (0.96 to 1.00$)$ & 0.99 (0.97 to 1.02$)$ \\
\hline \multirow[t]{2}{*}{ Gender } & Male & Ref & Ref \\
\hline & Female & 1.37 (0.86 to 2.20$)$ & 1.57 (0.88 to 2.79$)$ \\
\hline \multirow[t]{2}{*}{ Ethnicity } & Aboriginal & 1.58 (0.98 to 2.55$)$ & 2.39 (1.38 to 4.13$)$ \\
\hline & Other & Ref & Ref \\
\hline \multirow[t]{2}{*}{ Sexual orientation } & Straight & Ref & Ref \\
\hline & Gay/lesbian/homosexual/other & 1.39 (0.77 to 2.51$)$ & 0.54 (0.25 to 1.18$)$ \\
\hline \multirow[t]{3}{*}{ Neighborhood of residence } & Market/lowertown & 1.05 (0.66 to 1.68$)$ & 1.12 (0.63 to 1.98$)$ \\
\hline & Centretown & $0.36(0.2$ to 0.65$)$ & $0.45(0.2$ to 1.01$)$ \\
\hline & Other & Ref & Ref \\
\hline \multirow[t]{4}{*}{ Income quintile } & 1 and missing (lowest) & $1.3(0.66$ to 2.53$)$ & 1.13 (0.48 to 2.67 ) \\
\hline & 2 & 1.06 (0.53 to 2.14) & 0.91 (0.37 to 2.21) \\
\hline & 3 & 0.81 (0.39 to 1.68$)$ & 1.36 (0.55 to 3.35$)$ \\
\hline & 4 and 5 (highest) & Ref & Ref \\
\hline \multirow[t]{4}{*}{ Highest level of education } & Some HS or less & 1.22 (0.61 to 2.44$)$ & $1.07(0.44$ to 2.6$)$ \\
\hline & High school graduate or equivalent & 1.44 (0.7 to 2.93$)$ & 1.16 (0.46 to 2.92) \\
\hline & Some college or university & 2.14 (0.99 to 4.61$)$ & 1.72 (0.67 to 4.47$)$ \\
\hline & College or university completed & Ref & Ref \\
\hline \multirow[t]{3}{*}{ Prescription drug benefits } & Ontario Disability Support Program & 3.00 (1.65 to 5.45$)$ & 2.41 (1.08 to 5.39$)$ \\
\hline & Ontario Works & $2.74(1.5$ to 5.02$)$ & 2.15 (0.95 to 4.89) \\
\hline & Other, including no coverage & Ref & Ref \\
\hline \multirow[t]{2}{*}{ Sex work as primary source of income } & Yes & 0.52 (0.25 to 1.09$)$ & 1.03 (0.43 to 2.45) \\
\hline & No & Ref & Ref \\
\hline \multirow[t]{2}{*}{ Housing } & Unstable & 1.52 (0.96 to 2.42) & 1.85 (1.02 to 3.38$)$ \\
\hline & Stable & Ref & Ref \\
\hline \multirow{2}{*}{$\begin{array}{l}\text { Detained in jail overnight or longer in } \\
\text { the last } 12 \text { months }\end{array}$} & Yes & 1.62 (1.08 to 2.43$)$ & $0.97(0.58$ to 1.6$)$ \\
\hline & No & Ref & Ref \\
\hline \multirow[t]{3}{*}{ Drug use in past 12 months } & Any injection & 2.08 (1.26 to 3.43$)$ & 1.51 (0.79 to 2.88) \\
\hline & $\begin{array}{l}\text { Non-injection drug use (both opioids } \\
\text { and non-opioids) }\end{array}$ & 1.51 (0.87 to 2.62) & 2.21 (1.12 to 4.37$)$ \\
\hline & Non-injection use of only non-opioids & Ref & Ref \\
\hline \multirow[t]{2}{*}{ Overdosed in past 12 months } & Yes & $1.3(0.79$ to 2.14$)$ & 1.37 (0.76 to 2.47) \\
\hline & No & Ref & Ref \\
\hline \multirow[t]{2}{*}{ Comorbid HIV } & Yes & 1.57 (0.79 to 3.11$)$ & 2.54 (1.16 to 5.55$)$ \\
\hline & No & Ref & Ref \\
\hline \multirow[t]{2}{*}{ Last test for HCV result was positive } & Yes & 0.91 (0.58 to 1.43$)$ & $0.97(0.55$ to 1.71$)$ \\
\hline & No & Ref & Ref \\
\hline \multirow{2}{*}{$\begin{array}{l}\text { Comorbid mental health diagnosis } \\
\text { (excluding substance use-related } \\
\text { diagnoses) }\end{array}$} & Yes & 2.06 (1.35 to 3.14$)$ & 2.36 (1.31 to 4.24) \\
\hline & No & Ref & Ref \\
\hline \multirow[t]{2}{*}{ Attempted suicide in last 12 months } & Yes & 2.08 (1.13 to 3.83$)$ & 1.91 (0.97 to 3.74) \\
\hline & No & Ref & Ref \\
\hline \multirow[t]{2}{*}{ Currently on methadone } & Yes & 0.54 (0.34 to 0.88$)$ & 1.15 (0.64 to 2.08) \\
\hline & No & Ref & Ref \\
\hline
\end{tabular}


Table 5 Multivariable logistic regression of PROUD participant characteristics associated with 2+ emergency department visits or 1+ hospital admission, adjusted for listed covariates (Continued)

\begin{tabular}{llll}
\hline Accessed addiction treatment in past 12 months & Yes & 1 (0.67 to 1.5) & $0.97(0.58$ to 1.6) \\
& No & Ref & Ref \\
Has a regular family physician & Yes & 0.45 (0.23 to 0.86) & $1.02(0.45$ to 2.33) \\
& No & Ref & Ref \\
\hline
\end{tabular}

$A O R$ adjusted odds ratio

stability in mitigating this disparity in service use among PWUD. In addition, we recommend interventions to improve linkage to care post-incarceration among PWUD, and explicit evaluations of the impact of the criminal justice system on health care utilization.

\section{Abbreviations}

ADG: Aggregated Diagnosis Groups; CTAS: Canadian Triage and Acuity Score; HIV: Human immunodeficiency virus; ICES: Institute for Clinical Evaluative Sciences; OHIP: Ontario Health Insurance Program; OR: Odds ratio; PROUD: Participatory Research in Ottawa: Understanding Drugs; PWUD: People who use drugs; RR: Rate ratio

\section{Acknowledgements}

We thank IMS Brogan Inc. for the use of their Drug Information Database. Parts of this material are based on data and information compiled and provided by $\mathrm{ClHI}$. However, the analyses, conclusions, opinions and statements expressed herein are those of the author and not necessarily those of $\mathrm{ClHI}$.

We greatly acknowledge the contributions from the PROUD Community Advisory Committee, and all participants in the cohort study. We wish to acknowledge Christine Wakeham for her assistance in preparing our paper for submission.

\section{Funding}

This study was supported by the Institute for Clinical Evaluative Sciences (ICES), which is funded by an annual grant from the Ontario Ministry of Health and Long-Term Care (MOHLTC). The opinions, results, and conclusions reported in this paper are those of the authors and are independent from the funding sources. No endorsement by ICES or the Ontario MOHLTC is intended or should be inferred.

This project was also supported by grants from the Canadian Institutes of Health Research (CIHR), and the Ontario HIV Treatment Network (OHTN). Claire Kendall is supported by a CIHR-OHTN New Investigator Award. Ahmed Bayoumi is supported by the Fondation Alma and Baxter Ricard Chair in Inner City Health at St. Michael's Hospital, Toronto and the University of Toronto.

\section{Availability of data and materials}

ICES is a prescribed entity under Ontario's Personal Health Information Protection Act and is prohibited under its agreements with data providers, from contacting individuals whose information has been entrusted to ICES. ICES follows strict regulatory requirements to mitigate potential risk for reidentification, and researchers are only permitted to share ICES data tables that have not been approved for inclusion in this manuscript with ICES collaborating researchers or scientists on this specific project.

\section{Authors' contributions}

MT, CEK, and ZM wrote the initial study protocol for this project. All authors participated in developing the analysis plan. CEK, LMB, and AEM finalized the data creation plan. AEM conducted the analyses with guidance from CEK and $A M B$. All authors aided in interpreting the results. CEK and OL drafted the paper, with major revisions from $A M B$ and $L M B$. $L M B$ provided further edits to the manuscript, and CEK and AMB finalized all revisions. All authors approved the final version of the manuscript.
Competing interests

The authors declare that they have no competing interests.

\section{Consent for publication}

Consent to publish was obtained as part of informed consent.

Ethics approval and consent to participate

This study was approved by the institutional review board at Sunnybrook Health Sciences Centre, Toronto, Canada. The Ottawa Health Sciences Network Research Ethics Board (OHSN-REB \#20120566-01H) also approved this study. All participants included in the analyses provided consent for linkage of their survey data to databases at the Institute for Clinical Evaluative Sciences.

\section{Publisher's Note}

Springer Nature remains neutral with regard to jurisdictional claims in published maps and institutional affiliations.

\section{Author details \\ ${ }^{1}$ Bruyère Research Institute, 43 Bruyère Street (Annex E), Ottawa, ON K1N 5C8, Canada. ${ }^{2}$ Institute for Clinical Evaluative Sciences, Ottawa Hospital, Civic Campus, 1053 Carling Avenue, Box 684, Administrative Services Building, 1st Floor, Ottawa, ON K1Y 4E9, Canada. ${ }^{3}$ Ottawa Hospital Research Institute, 1053 Carling Avenue, Ottawa, Ontario K1Y 4E9, Canada. ${ }^{4}$ Social Development Studies and School of Social Work, Renison University College-University of Waterloo, 240 Westmount Road North, Waterloo, ON N2L 3G4, Canada. ${ }^{5}$ Sandy Hill Community Health Centre, 221 Nelson Street, Ottawa, ON K1N 1C7, Canada. 'Ottawa Public Health, 179 Clarence St, Ottawa, ON K1N 5P7, Canada. ${ }^{7}$ PROUD Community Advisory Committee, Ottawa, ON, Canada. ${ }^{8}$ Drug Users Advocacy League, Ottawa, ON, Canada. ${ }^{9} \mathrm{BC}$ Centre for Disease Control, 655W 12th Avenue, Vancouver, BC V5Z 4R4, Canada. ${ }^{10}$ Faculty of Medicine, University of Ottawa, 451 Smyth Rd, Ottawa, ON K1H 8 L1, Canada. \\ ${ }^{11}$ Centre for Urban Health Solutions, Li Ka Shing Knowledge Institute and Division of General Internal Medicine, St. Michael's Hospital, Toronto, Canada. ${ }^{12}$ Department of Medicine and Institute of Health Policy, Management, and Evaluation, University of Toronto, Toronto ON 30 Bond St, Toronto, ON M5B 1 W8, Canada.}

Received: 17 January 2017 Accepted: 15 March 2017 Published online: 12 May 2017

\section{References}

1. Degenhardt L, Whiteford HA, Ferrari AJ, et al. Global burden of disease attributable to illicit drug use and dependence: findings from the Global Burden of Disease Study 2010. Lancet. 2013;382(9904):1564-74. doi:10.1016/ S0140-6736(13)61530-5.

2. Mathers BM, Degenhardt L, Bucello C, Lemon J, Wiessing L, Hickman M. Systematic reviews mortality among people who inject drugs: a systematic review and meta-analysis. Bull World Heal Organ. 2013;91:102-23. doi:10. 2471/BLT.12.108282.

3. Millson P, Leonard L, Remis R, Strike C, Challacombe L. Injection Drug Use, HIV and HCV Infection in Ontario- The Evidence 1992-2004. Ontario; 2005.

4. Social support networks and primary care use by HIV-infected drug users.

5. Khandor E, Mason K, Chambers C, Rossiter K, Cowan L, Hwang SW. Access to primary health care among homeless adults in Toronto, Canada: results from the Street Health Survey. Open Med. 2011;5(2):94-103. 
6. Palepu A, Tyndall MW, Leon $\mathrm{H}$, et al. Hospital utilization and costs in a cohort of injection drug users. CMAJ. 2001;165(4):415-20.

7. Availability of medical care services in drug treatment clinics associated with lower repeated emergency department use.

8. Takahashi TA, Merrill JO, Boyko EJBK. Type and location of injection drug use-related soft tissue infections predict hospitalization. J Urban Heal. 2003; 80(1):127-36.

9. Asada $Y$, Kephart G. Equity in health services use and intensity of use in Canada. BMC Health Serv Res. 2007;7:41. doi:10.1186/1472-6963-7-41.

10. Roberts M, Hsiao W, Berman P, Michael R. Getting health reform right: a guide to improving performance. 1st ed. Loncon: Oxford University Press; 2008.

11. Rhodes T. Risk environments and drug harms- a social science for harm reduction approach. Int J Drug Policy. 2009;20:193-201.

12. Kerr T, Wood E, Grafstein E, et al. High rates of primary care and emergency department use among injection drug users in Vancouver. J Public Heal Vol. 2004;27(1):62-6. doi:10.1093/pubmed/fdh189.

13. Lundgren L, Chassler D, Ben-Ami L, Purington T, Schilling R. Factors associated with emergency room use among injection drug users of African-American, Hispanic and White-European background. Am J Addict. 2005;14(3):268-80. doi:10.1080/10550490590949442.

14. Binswanger IA, Takahashi TA, Bradley K, Dellit TH, Benton KL, Merrill JO. Drug users seeking emergency care for soft tissue infection at high risk for subsequent hospitalization and death. J Stud Alcohol Drugs. 2008;69(6):92432. doi:10.15288/jsad.2008.69.924.

15. Marshall BDL, Grafstein E, Buxton JA, et al. Frequent methamphetamine injection predicts emergency department utilization among street-involved youth. Public Health. 2012. doi:10.1016/j.puhe.2011.09.011.

16. Cunningham WE, Sohler NL, Tobias C. Health services utilization for people with HIV infection. Med Care. 2006;44(11):1038-47.

17. Stein MD, Anderson B. Injection frequency mediates health service use among persons with a history of drug injection. Drug Alcohol Depend. 2003. doi:10.1016/S0376-8716(02)00344-7.

18. Danielle Horyniak, Peter Higgs, Rebecca Jenkinson, Louisa Degenhardt, Mark Stoové TK, Matthew Hickman, Campbell Aitken PD. Establishing the Melbourne Injection Drug Cohort Study. Harm Reduct J. 2013;10(11). doi:10. 1186/1477-7517-10-11

19. Fairbairn N, Milloy M-J, Zhang R, et al. Emergency department utilization among a cohort of HIV-positive injecting drug users in a Canadian setting. J Emerg Med. 2012;43(2):236-43. doi:10.1016/j.jemermed.2011.05.020.

20. Parashar S, Chan K, Milan D, et al. The impact of unstable housing on emergency department use in a cohort of HIV-positive people in a Canadian setting. AIDS Care. 2014;26(1):53-64. doi:10.1016/j.biotechadv.2011.08.021.Secreted.

21. Mizuno Y, Wilkinson JD, Santibanez S, Dawson Rose C, Knowlton A, Handley K, Gourevitch MN, Inspire Team. Correlates of health care utilization among HIV-seropositive injection drug users. AIDS Care. 2006;18(5):417-25.

22. Sohler NL, Wong MD, Cunningham WE, Cabral H, Drainoni M-L, Cunningham CO. Type and pattern of illicit drug use and access to health care services for HIV-infected people. AIDS Patient Care STDS. 2007;21 Suppl 1:S68-76. doi:10.1089/apc.2007.9985.

23. Koeppe J, Lyda K, Armon C. Association between opioid use and health care utilization as measured by emergency room visits and hospitalizations among persons living with HIV. Clin J Pain. 2013;29(11):957-61. doi:10.1097/ AJP.0b013e31827c7b05.

24. Lloyd-Smith E, Wood E, Zhang R, et al. Determinants of hospitalization for a cutaneous injection-related infection among injection drug users: a cohort study. BMC Public Health. 2010;10:327. doi:10.1186/1471-2458-10-327.

25. Lloyd-Smith E, Tyndall M, Zhang R, et al. Determinants of cutaneous injectionrelated infections among injection drug users at an emergency department. Open Infect Dis J. 2012;6(1):5-11. doi:10.2174/1874279301206010005.

26. Takahashi TA, Baernstein A, Binswanger I, Bradley K, Merrill JO. Predictors of hospitalization for injection drug users seeking care for soft tissue infections. J Gen Intern Med. 2007;22(3):382-8. doi:10.1007/s11606-006-0079-y.

27. Trachtenberg AJ, Dik N, Chateau D, Katz A. Inequities in Ambulatory Care and the Relationship Between Socioeconomic Status and Respiratory Hospitalizations: A Population-Based Study of a Canadian City. Ann Fam Med. 2014:402-407. doi:10.1370/afm.1683.INTRODUCTION.

28. Lazarus L, Shaw A, LeBlanc S, et al. Establishing a community-based participatory research partnership among people who use drugs in Ottawa: the PROUD cohort study. Harm Reduct J. 2014;11(1).

29. Holmberg SD. The estimated prevalence and incidence of HIV in 96 large US metropolitan areas. Am J Public Health. 1996;86(5):642-54.
30. Opioid Use and Adverse Events in Ontario. Toronto, Ontario

31. Ontario Narcotics Atlas. Toronto, Ontario

32. Ury HK. Efficiency of case-control studies with multiple controls per case: continuous or dichotomous data. Biometrics. 1975;31(3):643-9.

33. The Johns Hopkins Adjusted Clinical Groups (ACG) System. Johns Hopkins University Press; 1997.

34. Steele LS, Glazier RH, Lin E, Evans M. Using administrative data to measure ambulatory mental health service provision in primary care. Med Care. 2004;42(10):960-5.

35. Antoniou T, Zagorski B, Loutfy MR, Strike C, Glazier RH. Validation of casefinding algorithms derived from administrative data for identifying adults living with human immunodeficiency virus infection. PLoS One. 2011;6(6):e21748.

36. Hutchison B, Glazier R. Ontario's primary care reforms have transformed the local care landscape, but a plan Is needed for ongoing improvement. Health Aff. 2013:32(4):695-703.

37. Singer MC, Erickson PI, Badiane L, et al. Syndemics, sex and the city: understanding sexually transmitted diseases in social and cultural context. Soc Sci Med. 2006;63(8):2010-21. doi:10.1016/j.socscimed.2006.05.012.

38. Rhodes T. The "risk environment": a framework for understanding and reducing drug-related harm. Int J Drug Policy. 2002;13(2):85-94. doi:10.1016/ S0955-3959(02)00007-5.

39. Sun BC, Burstin HR, Brennan TA. Predictors and outcomes of frequent emergency department users. Acad Emerg Med. 2003. doi:10.1197/aemj.10.4.320.

40. Mccusker J, Roberge D, Levesque JF, et al. Emergency department visits and primary care among adults with chronic conditions. Med Care. 2010;48(11): 972-80. doi:10.1097/MLR.0b013e3181eaf86d.

41. Trial AR, Sadowski LS, Kee RA, Vanderweele TJ, Buchanan D. Effect of a housing and case management program on emergency department visits and hospitalizations among chronically ill homeless adults: a randomized trial.

42. Mallik-Kane Christy Visher KA. Health and prisoner reentry: how physical, mental, and substance abuse conditions shape the process of reintegration. 2008.

43. Boyd AT, Song DL, Meyer JP AF. Emergency department use among HIVinfected released jail detainees.

44. Broadhead RS, Heckathorn DD, Weakliem DL, et al. Association of schools of public health harnessing peer networks as an instrument for AIDS prevention: results from a peer-driven intervention using populations: Current Status and Future Prospects (Jun., 1998), pp. 42-57 Published by: Association. Public Heal Reports. 1998;113(1):42-57.

45. Bowleg $\mathrm{L}$. The problem with the phrase women and minorities: intersectionality - an important theoretical framework for public health. Am J Public Health. 2012;102(7):1267-73. doi:10.2105/AJPH.2012.300750.

\section{Submit your next manuscript to BioMed Central and we will help you at every step:}

- We accept pre-submission inquiries

- Our selector tool helps you to find the most relevant journal

- We provide round the clock customer support

- Convenient online submission

- Thorough peer review

- Inclusion in PubMed and all major indexing services

- Maximum visibility for your research

Submit your manuscript at www.biomedcentral.com/submit
C BioMed Central 